\title{
Building Communication with Deaf Children during The Covid-19 Pandemic
}

\author{
Maulana Rezi Ramadhana ${ }^{1 *}$ Ravik Karsidi $^{2}$ Prahastiwi Utari ${ }^{3}$ Drajat Tri Kartono ${ }^{4}$ \\ 1,3,4 Faculty of Social and Political Science, Universitas Sebelas Maret, Surakarta, Indonesia \\ ${ }^{2}$ Faculty of Teacher Training and Education, Universitas Sebelas Maret, Surakarta, Indonesia \\ *Corresponding author. Email: maulanarezi@student.uns.ac.id
}

\begin{abstract}
The COVID-19 pandemic has changed the behavior of children with special needs. During this time, the role of family communication is important to maintain the children's development and resilience. This paper discusses the dynamics of family communication to cope with stress and to maintain the resilience of children with hearing impairment during isolation at home. Sixty-two deaf adolescents undergoing home quarantine were invited to answer questions online. Further, emotional reactions and family resilience were used as variables to obtain responses regarding their activities and communication within the family during isolation. The data were then analyzed by using simple frequency calculations to describe new realities. In this study, the number of family members at home was considered to decide family types. The results showed that (a) there was family interaction of deaf children through religious and house arrangement activities, with a stronger level from nuclear families, (b) deaf children felt more negative emotions in interactions in the family, (c) The existence of stronger family ties through the management of family relationships and communication was owned by deaf children from the nuclear family, and (d) stronger family belief systems were owned by deaf children from extended families. The conclusions of this study reveal different forms of interaction and emotional responses based on the family type of deaf children, the existence of relationship maintenance as a family protection factor, and emotional experiences as a form of adaptation to new normal situations. The findings in this study are important as an illustration for treating deaf children through interaction and communication approaches in dealing with adjustments to the new habits during the COVID19 pandemic
\end{abstract}

Keywords: family communication, resilience, deaf children, COVID-19.

\section{INTRODUCTION}

Family plays an important role to look after deaf children in protecting their rights to feel safe and providing facilities that support their development of difficulties. However, since the beginning of the COVID-19, the Indonesian government has implemented a protocol to prevent the spread of the virus through house isolation. This protocol results in several changes in the dynamics of family life for children with special needs. Home isolation is one of the main recommendations to minimize physical and social interactions between people and communities [1]. With all work and school activities carried out at home over a distance, the care for the development of children in the family becomes more challenging and has an impact on the relationship life in the family.

Many studies have examined the impact of isolation on the children such as mental health problems $[2][3][4][5][6]$, anxiety [7], public health [8][9], lifestyle [10], and social relations problems [11]. Furthermore, the home quarantine may also affect the children at the individual level such as depression [12], stress [13], irritability [14], anger [15], confusion [16], fear [17], sadness [18], anxiety [19], and other emotional disorders. Luckily, the role of the family is seemingly capable of reducing negative experiences due to psychological stress [20], interaction [21], and psychosocial support [11].

For families with deaf children, isolation is like a two-sided coin since it may serve as an opportunity as well as a threat in fulfilling the children's developmental needs, especially the need for education and health which is more than other normal children. By stopping the learning process at school and shifting the learning method at home, the family becomes a place of learning. Thus, the role of parents can be a guide for their children's education. 
Treatment for deaf and hearing-impaired children (DHH) needs to receive major attention during a pandemic [22], as it is a critical period in language development with a long impact.

During the pandemic, the learning experience of deaf children has been configured for a long time. The learningat-home concept is carried out remotely with the assistance of online technology [23]. This alternative method is considered easier for students so that they can learn independently and still interact with instructors and other students [24]. Although alternative methods are available, the challenges in preparing the method are frequently linked to technical difficulties that can hinder the learning process [25]. In addition, other researchers report that children do not feel comfortable learning online, which may cause them to feel frustrated [22]. In addition to learning support facilities and the availability of sign language translators, children also need more roles from parents to assist them. This situation seems to affect the emotional state of the child when he is with their family.

Parents' involvement is also increasing in fulfilling the health of their deaf children. During the pandemic, the children's hearing development therapeutic activities have also shifted to remote health services, such as telehealth [25]. Additionally, it is also generally shifted to care by parents in the family. The process of looking after deaf children in the family seems to be a learning process for parents and families to adapt to new norms [26]. The parents or family are required to succeed in applying several ways to overcome problems to achieve their family resilience [27]. On the other hand, families can show that they have more authority and are more effective in implementing family functions. New normal conditions during a pandemic can change family habits in interaction patterns [28], such as daily conversations [29] and new experiences in giving story messages [30] related to their difficulties face in the family.

The present paper attempts to address the emotional problems that arise and the interactions of the families to cope with the pressure of taking care of their deaf children during the pandemic. While research on the impact of selfisolation on the stress of normal individuals is available, the research investigating the attitudes of deaf children during the pandemic is scarce. This is so especially to those which study the interaction of activities and how family members can negotiate their relational world in building, enhancing, and optimizing crises and family barriers during the pandemic.

\section{LITERATURE REVIEW}

\subsection{Social Construction Theory}

Social construction is a theory that leads to social roles created through the use of language [31]. It focuses on how family members interact and negotiate their respective relational worlds. The theory pays special attention to understanding and interpreting patterns of interaction and related meanings. Social construction theory values family interactions as an important part of activities so that there is a reflective relationship between the individual level and the social level. By recognizing the nature and social reality that is built, there is an impact of the assumptions embedded in everyday communication. [28]. Previous research has found that nuclear families tend to have stronger intimacy and depend on communication in determining the roles and expectations of family members [32][33]. The social construction approach affirms that every family depends on discourse because they are subjected to interactions. They will greatly rely on interactions to make themselves communicative [32]. Social construction encourages the main role of communication on family traits which are seen as strengths when the family is part of a dependency that is created and legitimized in an interaction [34].

\subsection{Family system}

A family is a multidimensional unit that performs various functions in society. It includes various aspects such as family size, family function, and relationships between family members, etc. The definition of the family can be grouped based on the family structure [35][36]. Based on the family structure, the family is grouped into two types, named as the nuclear family, and the extended family [38]. The nuclear family is used to describe a family group consisting of father, mother, and children who live in one house. Meanwhile, the extended family is a large family system consisting of father, mother, and children, grandparents, aunts, uncles, and even some cousins who live together in one household. The function of the family based on the family system approach is also determined by intrapsychic factors, namely when a person finds himself, the push and pull, as well as emotional demands in the family. Apart from that, there are family roles and expectations, family boundaries and hierarchy, conflict, culture and family belief values. Resilience in the family system can act as a facilitator or a barrier to family health.

\subsection{Family Resilience}

Resilience is defined as the positive side of individual differences. It serves as a response to pressure and 
adversity [38]. Personal resilience in family members cannot be separated from family resilience [27], because it involves family functions. When deaf children face difficulties and are different from other children, they still have the capacity to generate resilience even though the treatment given by their families is a challenge. Recent research shows that many families still struggle to understand the situation of their children with disabilities and it has an impact on their children's development. Family resilience appears as integration of positive family behavior, including a function of competencies that must be held by each member of the family as a whole [39]. Other studies have shown that family resilience is considered a process that demonstrates the success of multiple families when coping strategies are used [40]. Family resilience refers to the active process of building, enhancing, and optimizing family crises and barriers [41]. The relational perspective as resilience assumes relationships in the adaptation process, maintains relationships, and increases individual resilience [41]. The concept of resilience is also inseparable from family communication serving as their main support. Therefore, it allows them to seek close interaction between them in producing a meaning. Family resilience also illustrates the relationship between beliefs and family organization systems, including the process of solving problems.

\section{METHODS}

\subsection{Participants}

This research involved 62 deaf adolescents who experienced independent isolation with their families at home. The sample was chosen by using a simple random sampling technique. Data on nuclear and extended family types (Reiss, 1988) were treated as family demographics. 93 deaf adolescents were initially invited to take part in an online survey. 74 participants responded to the invitation and 62 of them filled out the questionnaire. Respondents were well informed regarding the confidentiality of their responses. Then, the data was collected for 29 days (JuneJuly 2020) during the isolation period of COVID-19. The data was collected using an online questionnaire that was adapted from the literature mentioned in the earlier section. Respondents were asked to answer all items and consent was obtained from each participant. The data provided information about family demographics, family interactions in activities at home, emotional reactions [42][43] and family resilience [27] during the isolation period of COVID.-19.

\subsection{Measurement}

\subsubsection{Emotional reaction.}

Measures of emotional reactions of deaf children during the pandemic are categorized into two continuums: positive emotions and negative emotions [44]. Positive emotions include love [27], satisfaction [46], happiness [42], gratitude [47], entertainment [43], and relief [28]. Meanwhile, negative emotions are associated with anger \& fear [43], boredom [49], anxiety [50], sadness [51], and despair [52]. In this context, these positive and negative emotional reactions were measured through one item using a Likert scale, ranging from 1 (strongly disagree) to 5 (strongly agree)

\subsubsection{Family Resilience.}

The measure of family resilience includes three aspects: belief system, organizational pattern, and communication [41]. The belief system is assessed from three aspects: meaning-making (4 items), positive outlook (4 items), and transcendence ( 5 items). Further, organizational patterns are assessed from three aspects: flexibility (3 items), connectedness (2 items), and social support (4 items). Finally, communication is assessed from three aspects: communication (2 items), open emotional (4 items), and problem-solving (4 items). In this research, the measurement of family resilience employed a Likert scale, ranging from 1 (strongly disagree) to 5 (strongly agree). Finally, the data were analyzed with the help of statistical software, named SPSS (v.23.0) to produce descriptive statistics.

\section{RESULTS AND DISCUSSIONS}

Respondents in the study consisted of 34 nuclear families (54.8\%) and 28 extended families (45.2\%). Respondents reported that family interactions in religious activities (95.4\%), cleaning the house (95.1\%), making food $(85.1 \%)$, eating together $(69.6 \%)$, watching television $(56.8 \%)$, and exercise $(48.6 \%)$ were the six forms of family interaction during the isolation period of COVID19. The participation rate of the nuclear family $(76.7 \%)$ was higher than that of the extended family members $(56.6 \%)$

Table 1 : Positive Emotion, Negative Emotion and Family Resilience by Family Type

\begin{tabular}{|c|c|c|}
\hline \multicolumn{1}{|c|}{ Variable } & nuclear family & extended family \\
\cline { 2 - 3 } & $n=34$ & $n=28$ \\
\hline Positive Emotion & $\mathbf{6 0 . 5 \%}$ & $\mathbf{6 5 . 1 \%}$ \\
\hline Love & $64.1 \%$ & $64.3 \%$ \\
\hline Gratitude & $54.7 \%$ & $65.7 \%$ \\
\hline Happiness & $55.9 \%$ & $57.9 \%$ \\
\hline
\end{tabular}




\begin{tabular}{|l|l|l|}
\hline Entertainment & $52.9 \%$ & $77.1 \%$ \\
\hline Satisfaction & $53.5 \%$ & $57.1 \%$ \\
\hline Relief & $81.8 \%$ & $68.6 \%$ \\
\hline Negative Emotion & $\mathbf{6 2 . 2 \%}$ & $\mathbf{6 9 . 0 \%}$ \\
\hline Anxiety & $81.4 \%$ & $80.6 \%$ \\
\hline Sadness & $42.5 \%$ & $77.6 \%$ \\
\hline Anger & $71.2 \%$ & $46.4 \%$ \\
\hline Despair & $45.9 \%$ & $53.6 \%$ \\
\hline Fear & $53.5 \%$ & $76.5 \%$ \\
\hline Boredom & $78.8 \%$ & $79.4 \%$ \\
\hline Belief System & $\mathbf{6 8 . 6 \%}$ & $\mathbf{7 4 . 8 \%}$ \\
\hline Making meaning & $71.2 \%$ & $77.9 \%$ \\
\hline Positive Outlook & $69.4 \%$ & $67.1 \%$ \\
\hline Transcendence & $65.3 \%$ & $79.3 \%$ \\
\hline Organizational Pattern & $\mathbf{7 6 . 9 \%}$ & $\mathbf{6 7 . 1 \%}$ \\
\hline Flexibility & $78.8 \%$ & $64.3 \%$ \\
\hline Connectedness & $77.1 \%$ & $60.0 \%$ \\
\hline Social resources & $74.7 \%$ & $77.1 \%$ \\
\hline Communication \& Problem Solving & $\mathbf{7 7 . 4 \%}$ & $\mathbf{5 7 . 9 \%}$ \\
\hline Communication & $77.6 \%$ & $66.4 \%$ \\
\hline Open emotional & $76.5 \%$ & $52.9 \%$ \\
\hline roblem Solving & $78.2 \%$ & $54.3 \%$ \\
\hline & & \\
\hline
\end{tabular}

Emotion measurement results show that the extended family $(65.1 \%)$ has more positive emotions than the nuclear family $(60.5 \%)$. The types of positive emotions that were stronger in the extended family were entertainment $(77.1 \%)$, gratitude $(65.7 \%)$, love $(64.3 \%)$, and happiness $(57.9 \%)$. Meanwhile, the stronger positive emotions appearing in the nuclear family are relief $(81.8 \%)$. Negative emotions appear stronger in extended families $(69 \%)$ than nuclear families $(62.2 \%)$, with stronger emotions of sadness $(77.6 \%)$, boredom $(79.4 \%)$, and fear $(76.5 \%)$ owned by the extended family. Meanwhile anxiety $(81.4 \%)$ and anger $(71.2 \%)$ are more owned by the nuclear family. In family resilience, the belief system aspect is stronger in the extended family $(74.8 \%)$ than the nuclear family $(68.6 \%)$, while the organizational pattern aspect is stronger in the nuclear family $(76.9 \%)$ than the extended family $(67.1 \%)$, and the communication aspect is stronger by the nuclear family $(77.4 \%)$ than the extended family $(57.9 \%)$.

Negative emotions experienced by deaf children appeared in both types of families. Furthermore, deaf children from extended families showed more emotional reactions (both positive and negative) than deaf children from nuclear families. Although they did not have a significant difference, the two types of families had different types of emotional reactions, such as anxiety, boredom, sadness, and relief experienced by deaf children in the nuclear family type, while anxiety, boredom, entertainment, fear, and sadness were emotions existed in deaf children in the extended family type. Family resilience through aspects of family management patterns and family communication was reported stronger by nuclear families, while family's belief systems were more frequently found in the extended family types.

Family interaction is one of family's coping strategies aiming to maintain relationships between families [53]. Based on joint activities reported by deaf children, mutual interactions through religious activities and making food was a routine performed by the family during the COVID-19 pandemic. As a country with the largest Muslim population in the world, collective religious activities (such as prayer) were in line with the collective culture in Indonesia [54]. This finding confirmed the results that the aspect of religion could not be separated in dealing with the spread of COVID-19. Religious activities were believed to be the solution to the outbreak that occurred in Indonesia [55]. Intergenerational exchanges in the family, unexpected thoughts, and messages could occur during the isolation period of COVID-19 so that turbulence might occur among family members. The turbulence might have an impact on the mood of family members who were not positive in responding to situations in the family. Previous research has found that there was a higher risk of anxiety from families who like to stay at home during isolation [56], possibly referring to all family types found in the results of this study.

The nuclear family type was considered to have a more communal orientation than other family types. In this study, the type of family showed more involvement and communication in activities at home which was exemplified through the predominance of hopeful emotional reactions. These findings explained social constructs that were similar to research results that led to strong closeness and communication in the nuclear family [32][33] The extended family type which was more encouraging for member participation in the family [57], which is explained by the emotional reactions of joy and enthusiasm. The extended family is a type of family with large members. It will certainly increase the number of interactions that affect emotional color, both encouraging positive and negative emotions. In addition, this family tip can encourage emotional support and protection from both immediate and non-nuclear family members. The extended family relationship pattern can be carried out autonomously influenced by the kinship system of other family members as social support so that the family belief system in the findings of this study can be used to optimize family crises and barriers [41].

The rearing of deaf children in the family during the COVID-19 pandemic has indicated that mutual interaction and attachment have created a better understanding of the function of family care and affection. The role of the family in taking care of deaf children seems to be related to the attitude of how families form relationship patterns with their deaf children. Meanwhile, their deaf children's needs in mentoring, relationship maintenance, emotions, and family attachment styles have shown coping abilities to achieve their self-identity in the family. A new social reality in their family life strengthens positive emotions during the isolation of COVID-19. Such emotions can be built through conversation and social support. Family communication plays a role as a form of maintaining relationships with deaf children and is an important and meaningful component in building self-reliance and families of children with special needs during the COVID19 pandemic in Indonesia. 


\section{CONCLUSION}

This study leads to several key findings. First, family interactions exist among deaf children through religious and household activities with a stronger level of participation from nuclear families. Second, deaf children feel more negative emotions in interactions in the family. Following this, there is a family attachment through the management of family relationships and communication owned more strongly by deaf children from nuclear families. Finally, a stronger family belief system is owned by deaf children from extended families. The study then concluded that there were different forms of interaction and emotional responses based on the family type of deaf children, the existence of relationship maintenance as a family protection factor, and emotional experiences as a form of adaptation to new normal situations. Family care strategies in building positive interactions and communication are very meaningful in building resilience for children and families with special needs. The findings in this study are important as an illustration of how deaf children are taken care of through family interaction and communication approaches during the COVID-19 pandemic. As long as there is no certainty about the COVID-19 pandemic situation, maintaining relationships and closeness must be maintained to meet the needs of deaf children, and it needs to be developed in improving the quality of family health for children's personal development in facing some adjustments in the new normal times

\section{REFERENCES}

[1] WHO (2020), "WHO press briefing on COVID19," WHO Press Brief. COVID-19, vol. 1, no. physical distancing as one measure to stop COVID-19 transmission

[2] Ho, C. S., Chee, C. Y., \& Ho, R. C. (2020). Mental Health Strategies to Combat the Psychological Impact of COVID-19 Beyond Paranoia and Panic. Annals of the Academy of Medicine, Singapore, 49(1), 1-3

[3] Liu, J. J., Bao, Y., Huang, X., Shi, J., \& Lu, L. (2020). Mental health considerations for children quarantined because of COVID-19. The Lancet Child and Adolescent Health, Vol. 4, pp. 347-349. https://doi.org/10.1016/S2352- 4642(20)30096-1

[4] Setiati, S., \& Azwar, M. K. (2020). COVID-19 and Indonesia. Acta Medica Indonesiana, 52(1), 84-89.

[5] Wang, C., Pan, R., Wan, X., Tan, Y., Xu, L., Ho, C. S., \& Ho, R. C. (2020). Immediate psychological responses and associated factors during the initial stage of the 2019 coronavirus disease (COVID-19) epidemic among the general population in China. International Journal of Environmental Research and

Public Health, 17(5).

https://doi.org/10.3390/ijerph17051729

[6] Yang, Y., Li, W., Zhang, Q., Zhang, L., Cheung, T., \& Xiang, Y. T. (2020). Mental health services for older adults in China during the COVID-19 outbreak. The Lancet Psychiatry, Vol. 7, p. e19. https://doi.org/10.1016/S2215-0366(20)300791

[7] Brooks, S. K., Webster, R. K., Smith, L. E., Woodland, L., Wessely, S., Greenberg, N., et al. (2020). The psychological impact of quarantine and how to reduce it: rapid review of the evidence. Lancet 395, 912-920. doi: 10.1016/S0140- 6736(20)30460-8

[8] Dong, L., \& Bouey, J. (2020). Public Mental Health Crisis during COVID-19 Pandemic, China. Emerging Infectious Diseases, 26(7). https://doi.org/10.3201/eid2607.200407

[9] Tsai, J., \& Wilson, M. (2020). COVID-19: a potential public health problem for homeless populations. The Lancet Public Health, Vol. 5, pp. e186-e187. https://doi.org/10.1016/S24682667(20)30053-0

[10] Dani, J. A., \& Mediantara, Y. (2020). Covid-19 Dan Perubahan Komunikasi Sosial. Persepsi: 3(1), 94 102. https://doi.org/10.30596/persepsi.v3i1.4510

[11] Tanoue, Y., Nomura, S., Yoneoka, D., Kawashima, T., Eguchi, A., Shi, S., ... Miyata, H. (2020). Mental health of family, friends, and coworkers of COVID-19 patients in Japan. Psychiatry Research, 113067.

\section{https://doi.org/10.1016/j.psychres.2020.113067}

[12] Hawryluck, L., Gold, W. L., Robinson, S., Pogorski, S., Galea, S., \& Styra, R. (2004). SARS control and psychological effects of quarantine, Toronto, Canada. Emerging Infectious Diseases, 10(7), 1206-1212. https://doi.org/10.3201/eid1007.030703

[13] DiGiovanni, C., Conley, J., Chiu, D., \& Zaborski, J. (2004). Factors influencing compliance with quarantine in Toronto during the 2003 SARS outbreak. Biosecurity and Bioterrorism: Biodefense Strategy, Practice, and Science, 2(4), 265-272. https://doi.org/10.1089/bsp.2004.2.265 
[14] Lee, S., Chan, L. Y. Y., Chau, A. M. Y., Kwok, K. P. S., \& Kleinman, A. (2005). The experience of SARSrelated stigma at Amoy Gardens. Social Science and Medicine, $\quad 61(9), \quad 2038-\quad 2046$. https://doi.org/10.1016/j.socscimed.2005.04.010

[15] Marjanovic, Z., Greenglass, E. R., \& Coffey, S. (2007). The relevance of psychosocial variables and working conditions in predicting nurses' coping strategies during the SARS crisis: An online questionnaire survey. International Journal of Nursing Studies, 44(6), 991-998. https://doi.org/10.1016/j.ijnurstu.2006.02.012

[16] Pan, P. J. D., Chang, S. H., \& Yu, Y. Y. (2005). A support group for home-quarantined college students exposed to SARS: Learning from practice. Journal for Specialists in Group Work, 30(4), 363-374.

https://doi.org/10.1080/01933920500186951

[17] Caleo, G., Duncombe, J., Jephcott, F., Lokuge, K., Mills, C., Looijen, E., ... Greig, J. (2018). The factors affecting household transmission dynamics and community compliance with Ebola control measures: A mixed-methods study in a rural village in Sierra Leone. BMC Public Health, 18(1). https://doi.org/10.1186/s12889-018-5158-6

[18] Wang, Y., Xu, B., Zhao, G., Cao, R., He, X., \& $\mathrm{Fu}$, S. (2011). Is quarantine related to immediate negative psychological consequences during the 2009 H1N1 epidemic? General Hospital Psychiatry, 33(1), 75-77.

https://doi.org/10.1016/j.genhosppsych.2010.11.001

[19] Desclaux, A., Badji, D., Ndione, A. G., \& Sow, K. (2017). Accepted monitoring or endured quarantine? Ebola contacts' perceptions in Senegal. Social Science and Medicine, $178, \quad 38-\quad 45$. https://doi.org/10.1016/j.socscimed.2017.02.009

[20] Hart, J. L., Turnbull, A. E., Oppenheim, I. M., \& Courtright, K. R. (2020). Family-Centered Care During the COVID-19 Era. Journal of Pain and Symptom Management, 60(2), e93e97.

\section{https://doi.org/10.1016/j.jpainsymman.2020.04.017}

[21] Avasthi, A. (2010). Preserve and strengthen family to promote mental health. Indian journal of psychiatry, 52(2), 113.

[22] Pattisapu P, Evans SS, Noble AR, et al. (2020). Defining Essential Services for Deaf and Hard of
Hearing Children during the COVID-19 Pandemic. Otolaryngology-Head and Neck Surgery.163(1):91-93. doi:10.1177/0194599820925058

[23] McBrien, Jody \& Rui, Cheng \& Jones, Phyllis. (2009). Virtual Spaces: Employing a Synchronous Online Classroom to Facilitate Student Engagement in Online Learning. International Review of Research in Open and Distance Learning. 10. 10.19173/irrodl.v10i3.605.

[24] Vandana Singh \& Alexander Thurman (2019) How Many Ways Can We Define Online Learning? A Systematic Literature Review of Definitions of Online Learning (1988- 2018), American Journal of Distance Education, 33:4, 289- 306, DOI: $\underline{10.1080 / 08923647.2019 .1663082}$

[25] Favale, T., Soro, F., Trevisan, M., Drago, I., Mellia, M. (2020). Campus traffic and eLearning during COVID-19 pandemic. Computer Networks, 176, 10729026CDS, 2020

[26] Buzzanell, P. M. (2018). Communication Theory of Resilience. In Engaging Theories in Family

[27] Walsh, F. (1996). The Concept of Family Resilience: Crisis and Challenge. Family Process, 35(3), 261-281 https://doi.org/10.1111/j.15455300.1996.00261.x

[28] Baxter, L. A. (2004). Relationships as dialogues. Personal Relationships, 11, 1-22.

[29] Tovarez, A. V. (2010). All in the family: Small stories and narrative construction of a shared family identity that includes pets. Narrative Inquiry, 20, 1-19.

[30] Trees, A. R., \& Koenig Kellas, J. (2009). Telling tales: Enacting family relationships in joint storytelling about difficult family experiences. Western Journal of Communication, 73, 91-113.

[31] Leeds-Hurwitz, W. (2006). Social theories: Social constructionism and symbolic interactionism. InD. O. Braithwaite \& L. A. Baxter (Eds.), Engaging theories in family communication: Multiple perspectives (pp. 229-242).

Thousand Oaks, CA: Sage

[32] Baxter, L. A. (2014). Theorizing the communicative construction of "family": The threeR's. In L. A. Baxter (Ed.), Remaking "family" communicatively (pp. 33-50). New York,

NY: Peter Lang 
[33] Galvin, K. M. (2006). Diversity's impact on defining the family. In L. H. Turner \& R. West (Eds.), The family communication sourcebook (pp. 3-19). Thousand Oaks, CA: Sage.

[34] Galvin, K. M., \& Braithwaite, D. O. (2014). Family communication theory and research from the field of family communication: Discourses that constitute and reflect families.

Journal of Family Theory \& Review, 6, 97-111

[35] Wamboldt, F. S., \& Reiss, D. (1989). Defining a family heritage and a new relationship identity:Two central tasks in the making of a marriage. Family Process, 28(3), 317-335.

[36] Noller, P., \& Fitzpatrick, M. A. (1993). Communication in family relationships. Englewood Cliffs, CA: Prentice Hall.

[37] Reiss, D., \& Oliveri, M. E. (1983). The family's construction of social reality and its ties to its kin network: An exploration of causal direction. Journal of Marriage and the Family, 81-91.

[38] Rutter, M. (1987). Psychosocial Resilience and Protective Mechanisms. American Journal of Orthopsychiatry, $\quad 57, \quad 316-\quad 331$. http://dx.doi.org/10.1111/j.1939-0025.1987.tb03541.x

[39] McCubbin, H. I., \& McCubbin, M. A. (1988). Typologies of resilient families: Emerging roles of social class and ethnicity. Family relations, 247-254

[40] McCubbin, H., McCubbin, M., \& Thompson, E. (1995). Resiliency in ethnic families: A conceptual model for predicting family adjustment and adaptation. In H. McCubbin,

M. McCubbin, A. Thompson, \& J. Fromer (Eds.), Resiliency in ethnic minority families (Vol. 1, pp. 348). Madison, WI: University of Wisconsin Press

[41] Walsh, F. (2016). Family resilience: a developmental systems framework. European Journal of Developmental Psychology. https://doi.org/10.1080/17405629.2016.1154035

[42] Ekman, P. (2005). Basic Emotions. In Handbook of Cognition and Emotion (pp. 4560). https://doi.org/10.1002/0470013494.ch3

[43] Fredrickson, B. L. (2003). The value of positive emotions. American Scientist, 91(4), 330-335. https://doi.org/10.1511/2003.4.330
[44] Tellegen, D. Watson, and L. A. Clark, (1999), "On the dimensional and hierarchical structure of affect," Psychol. Sci., vol. 10, no. 4, pp. 297-303

[45] Lamy, (2014), "Beyond emotion: Love as an encounter of myth and drive," Emotion Review, vol. 8, no. 2. pp. 97-107

[46] Campos, Ullman, Aguilera, and Dunkel Schetter (2014), "Familism and psychological health: the intervening role of closeness and social support," Cultur. Divers. Ethnic Minor.

Psychol., vol. 20, no. 2, pp. 191-201

[47] Armenta, Fritz, and Lyubomirsky, (2017), "Functions of Positive Emotions: Gratitude as a Motivator of Self- Improvement and Positive Change," Emot. Rev., vol. 9, no. 3, pp. 183-190

[48] 52 Schoder, (2003), "Experimental study of affect bursts," Speech Commun., vol. 40, no. 1-2, pp. 99-116.

[49] Pekrun et al., (2010), Pekrun, T. Goetz, L. M. Daniels, R. H. Stupnisky, and R. P. Perry, "Boredom in Achievement Settings: Exploring Control-Value Antecedents and Performance Outcomes of a Neglected Emotion," J. Educ. Psychol., vol. 102, no. 3, pp. 531549.

[50] Basso, Schefft, Ris, and Dember, (1996), "Mood and global-local visual processing," J. Int. Neuropsychol. Soc., vol. 2, no. 3, pp. 249-255

[51] Parrott, W. G. (Ed.). (2001). Emotions in social psychology: Essential readings. Psychology Press.

[52] Pekrun and Perry (2014), "Control-value theory of achievement emotions," in International Handbook of Emotions in Education, pp. 120-141

[53] Afifi, T. D., Merrill, A. F., \& Davis, S. (2016). The theory of resilience and relational load. Personal Relationships, 23(4), 663-683. https://doi.org/10.1111/pere.12159

[54] Benedictus, R. A. (2018). Occupational Stress and Coping Strategy Harmony Between Scientific Theory and Islamic Teachings And Practice. Manasa-old, 7(1), 51-61.

[55] Djalante, R., Lassa, J., Setiamarga, D., Sudjatma, A., Indrawan, M., Haryanto, B., ... Warsilah, H. (2020). Review and analysis of current responses to COVID-19 in Indonesia: Period of January to March 2020. Progress in Disaster Science, 6, 100091. https://doi.org/10.1016/j.pdisas.2020.100091 
[56] Oosterhoff, B., Palmer, C. A., Wilson, J., \& Shook, N. (2020). Adolescents' Motivations to Engage in Social Distancing during the COVID-19 Pandemic: Associations with Mental and Social Health. Journal of Adolescent https://doi.org/10.1016/j.jadohealth.2020.05.004

[57] Jansen, K. (2017). Extended Family Relationships: How They Impact the Mental Health of Young Adults. https://doi.org/10.13023/ETD.2017.102 